\title{
The design and application of comprehensive experimental platform for custom power equipment
}

\author{
Yeniu Qian ${ }^{\text {a }, ~ J i a n ~ S u n, ~ Y a n ~ Z h a n g ~ a n d ~ D o n g q i a n g ~ J i a ~}$ \\ State Grid Beijing Electric Power Research Institute, 100075 Fengtai, Beijing, China
}

\begin{abstract}
The Comprehensive Experimental Platform for Custom Power Equipment is designed based on voltage source power quality disturbance device, current source power quality disturbance device and phase shifter. Actual operating performance of Solid State Transfer Switch, Dynamic Voltage Restorer and Flywheel Energy Storage Device are experimentally analysed by the experimental platform. The experimental platform has the advantage of functional, flexible and expansion. In addition, The Experimental Platform Can be used to study factory experiment, handover experiment and maintenance technology of Active Power Filter, Static Synchronous Compensator and so on.
\end{abstract}

Keywords: solid state transfer switch; dynamic voltage restorer; flywheel energy storage device; custom power.

\section{Introduction}

With the rapid development of modern science and technology, nonlinear load and impact load are widely used by terminal user .Distribution network power quality are contaminated seriously and destroyed. In addition, the control equipment and electrical device based on Microprocessor and Microcomputer appear in mass.For example, frequency conversion equipment, programmable controller, precision CNC machine and information management system are widely used in bank, data center, precision machine process and semiconductor manufacturing, result in power system power quality sensitively. Especially, voltage dips not only affects user's production ,but also bring about severe economic loss directly or indirectly. So it is imminent to improve distribution network power quality.

For the distribution system power quality problems, relying on modern power electronics and control technology, custom power technology emerges. The so-called custom power technology, also known as user power technology, proposed by Palo Alto firstly, the expert of American Electric Power Research Institute, has been rapid developed and applied all over the world. It is mainly based on high-power electronic switching devices, and adopts microprocessor, optical fiber communication, digital signals processing power electronic controller is used for $1-38 \mathrm{kV}$ distribution network to provide the reliability and better power quality which meet users requirements. custom power technology can provide 'needed power' for users, even users are strict to power quality. Controller adopting custom power technology is called custom power equipment. such as Solid State Transfer Switch(SSTS), Dynamic Voltage Restorer(DVR), Active Power Filter(APF), Static Synchronous

\footnotetext{
${ }^{\text {a }}$ Corresponding author : gotoqianyeniu@163.com.
} 
Compensator(STATCOM), Unified Power Quality Conditioner(UPQC) ,Flywheel Energy Storage Device(FESD) and so on.

It is early to study the custom power technology abroad,and there are some outstanding achievement. Custom power equipment is in piloting application stage in domestic. Product's functional and performance is lack of complex long-running test. Custom power equipment's experimental study with different characteristic loads is not enough in various conditions. The best performance of custom power equipment is affected easily by various factors, the actual operating performance, high power quality and high reliability to sensitive loads are determined by experimental study. The comprehensive Experimental Platform is designed and experimental study is operated to improve the ability about study and detecting.

\section{Custom power equipment introduction}

There are typical custom power equipment in distribution network, such as SSTS, DVR, APF, STATCOM, FESD ,UPQC and so on. Now, we will introduce some important equipment from these custom power equipment.

\subsection{SSTS introduction}

SSTS consist of parallel fast switches PS1 and PS2, anti-parallel thyristor switches TS1 and TS2, power load's switches Q0, Q1, Q2. it's basic structure is shown in figure-1.

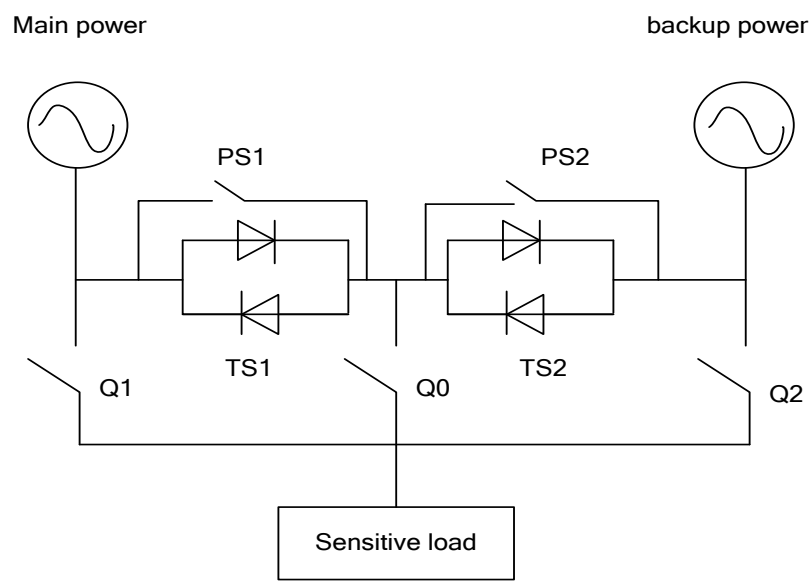

Figure 1. SSTS structure diagram

Main power supplies power for load, the parallel high speed mechanical switch PS1 is turned on. Thyristor switch TS1 is bypassed, Power switch Q0 is turned on. SSTS control system sends switch order, PS1 is turned off, TS1 is turned on, when main power voltage occurs an exception . Current is shifted to thyristor immediately. There is little arc, if not, arc will be snubbed out because of thyristor's turning on when PS1 is turned on. Thyristor will be turned off when current cross 0 firstly at the condition that TS1's trigger signal has been withdrew.Then TS2 is turned on and supplied by backup power. At this time, the switch has been completed. After a period of time to be stabilized ,the control system send order to turn on PS2, TS2 is in the state of turn on and the voltage is closed to 0 . the arc will not be generated when PS2 is turned on .when SSTS need to be maintained ,load is supplied uninterruptedly by power switch Q1 and Q2. SSTS implements two incoming feeder's millisecond switch, voltage dips and short-term power interruption can be solved. User's loss is reduced to ensure reality power supply. 


\subsection{DVR introduction}

DVR consist of energy storage unit, DC voltage stabilization unit, fully - controlled inverter and series transformer, it's basic structure is shown in figure -2. DVR is connected between power grid and sensitive loads. when the distribution network is normal, device's energy loss is little. Load voltage can be compensated by DVR in millisecond when power grid voltage dips signal is detected by system .Sensitive load voltage can be restored to normal value. DVR is in standby state to make sensitive load's voltage reliability. Because DVR only compensate the part of voltage dips shortfall, it is known as effective device to ensure high voltage quality for sensitive load and it is very useful in eliminating voltage dips, enhancing power quality for big sensitive industrial load.

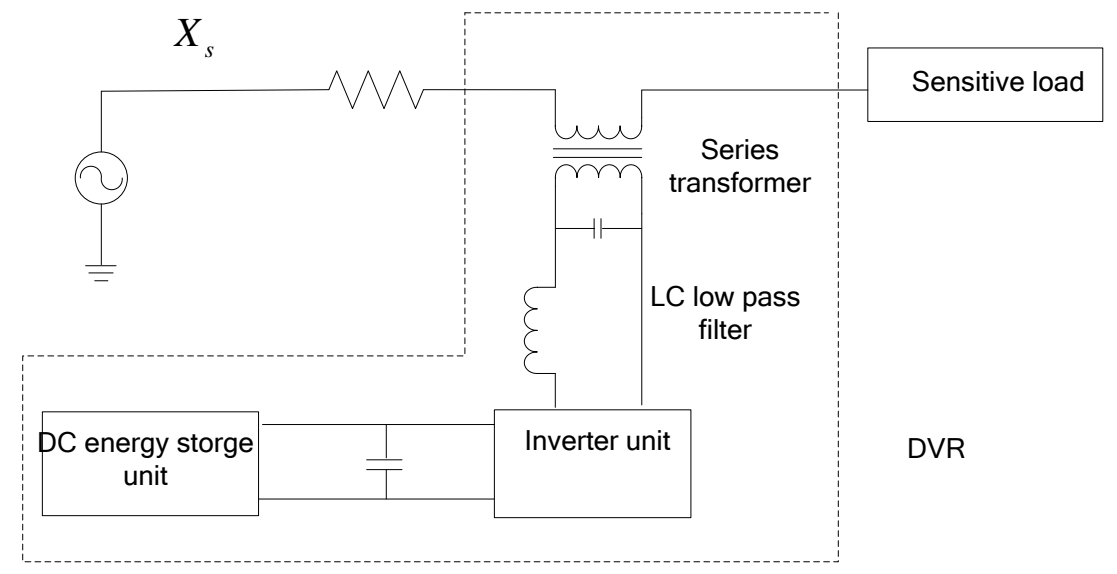

Figure 2. DVR structure diagram

\subsection{APF introduction}

APF is a new electronic power electronic device to dynamic control harmonic and compensate reactive power. It can detect harmonic current from harmonic source load and generate an equal and opposite direction harmonic current to restrain harmonic current to flow into power grid. The advantages of APF are fast dynamic response, more compensation function and its characteristic is not affected by power grid parameter, so it has been widely studied and applied all over the world. There are many types of APF, in fact voltage-shunt APF is widely used in AC power system. Its structure is shown in figure-3.

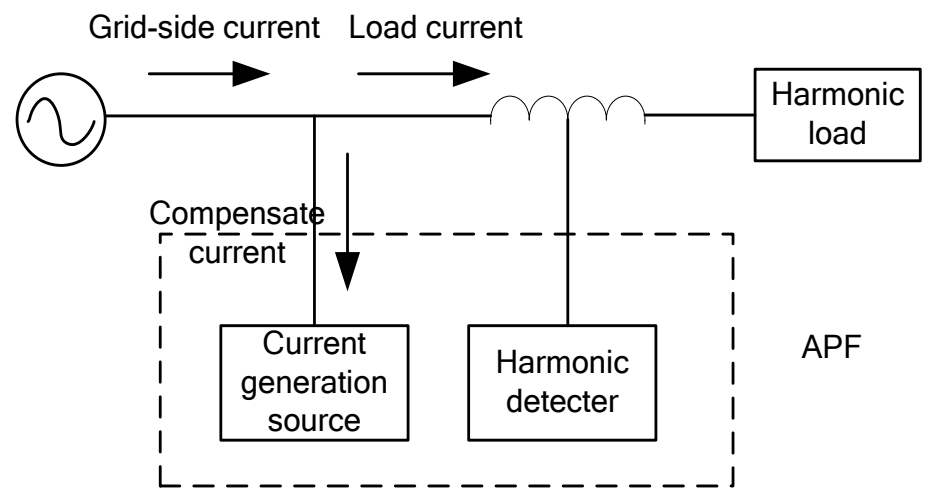

Figure 3. APF structure diagram 


\subsection{STATCOM introduction}

The basic principle of STATCOM is that three-phase bridge converter circuit is installed on load side bus in parallel, then the amplitude and phase of three-phase bridge circuit's output voltage and current are adjusted. Then satisfied reactive current is absorbed or generated to dynamic compensate reactive power. According to the different energy storage device on DC side, STATCOM can be classified voltage - STATCOM and current- STATCOM. The structure of normal voltage-mode STATCOM is shown in figure-4.

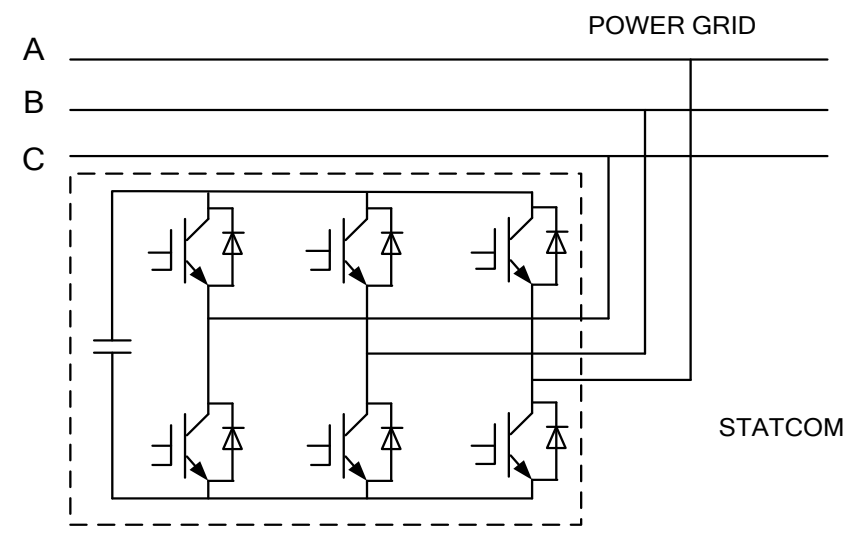

Figure 4. STATCOM structure diagram

\subsection{FESD introduction}

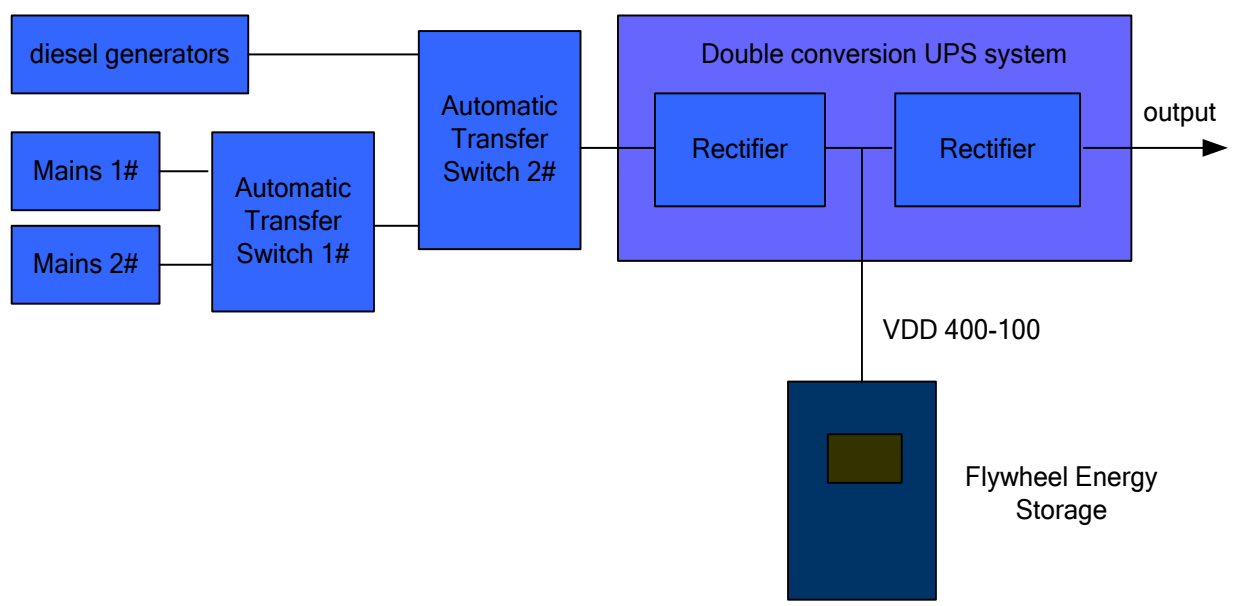

Figure 5. FESD structure diagram

The structure of FESD is shown in figue-5. AC is transformed to DC when it is pass the rectifier. Internal DC is responsible for the Flywheel energy storage and supplies power for inverter. DC is inversed to high quality AC for load by inverter. Sometimes three source input is adopted to Maximum increase power reliability,although it's a redundancy pattern. From mains\#1 to mains\#2 and then diesel generators is set.

When input mains break down,FESD releases energy supplies power for inverter so that high quality AC is supplied to load by inverter, at same time diesel generators is started in 6-8 second and energy is transported to rectifier. diesel generators continues to run for a period of time when mains 
recovery. Diesel generators can run 8 hours at least in the case of mains interruption, because it is equipped with a fuel tank.

\section{The design and achievement of Comprehensive Experimental Platform for Custom Power Equipment}

According to custom power equipment various structure, the ways of joining the lines of Comprehensive Experimental Platform for Custom Power Equipment is shown in figure-6. There are three kinds of power quality disturbance device connected to experiment platform such as voltagemode power quality disturbances device ,current-mode power quality disturbance device, phase shifter, their parameter is shown in table-1to table-3.others is shown in table-4. Power switches located in Experimental Platform are installed in a distribution Cabinet to operating flexible operating. In addition, all custom power equipment are connected to the power switches utilizing quick connector and dedicated soft cable to improve the flexibility of platform. Different types of custom power equipment testing are achieved through different combination of power switch.

1) SSTS TEST: turn on QF1, QE3, QF7, QF2, QF4, QF8, QF9, QF11, QF13, QF17, QF18. Set phase shifter. Prove the affection of different power supplies to SSTS's switching time.Set voltagemode power quality disturbance device, test SSTS response time ,voltage dips and mains interruption treatment effect.

2) DVR TEST: turn on QF1, QF3, QF7, QF9,SSTS bypass repairing switch,QF13, QF15, QF16, QF18. Set voltage-mode power quality disturbance device, test DVR response time and Voltage dips treatment effect.

3) APF TEST: turn on QF1, QF5, QF9,SSTS bypass repairing switch,QF13, QF17, QF19, QF21. Set current-mode power quality disturbance device, test APF response time and filter effect.

4) STATCOM test : turn on QF1, QF5, QF9,SSTS bypass repairing switch,QF13, QF17, QF18, QF20. Set loads with different power factor, test STATACOM response time and power factor improving effect.

5) FESD test: turn on QF1, QF3, QF7,QF2, QF4,QF8,QF10,QF12,QF14,QF17,QF18.Set phase shifter. Prove the affection of different power supplies to FESD's switching time. Set voltage-mode power quality disturbance device, test FESD response time, voltage dips and power supply discontinue managing effect.

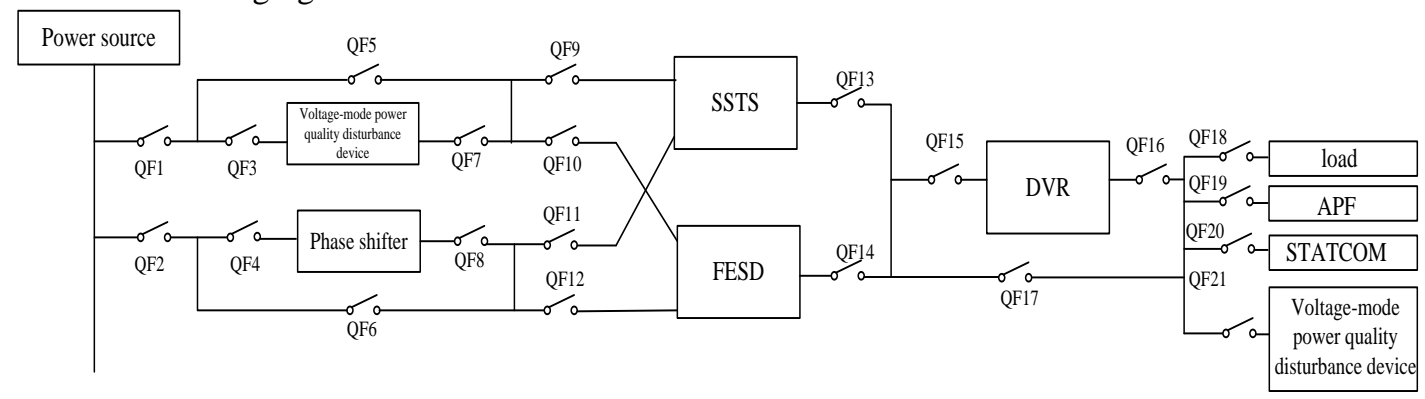

Figure 6. Wiring Diagram of Comprehensive Experimental Platform for Custom Power Equipment 
Table 1. Voltage-mode power quality disturbances device parameter

\begin{tabular}{|c|c|}
\hline rated voltage & AC380V $\pm 10 \%$ \\
\hline rated frequency & $47 \sim 63 \mathrm{~Hz}$ \\
\hline connecting method & three-phase four-wire system \\
\hline Swells amplitude & $110 \%-140 \%$ \\
\hline Dips amplitude & $0 \%-90 \%$ \\
\hline $\begin{array}{c}\text { Swells } \\
\text { dips set }\end{array}$ & $\begin{array}{c}\text { Three-phase simultaneously set ,split phase set, initial phase angle of swells } \\
\text { and dips set ,duration of swells and dips set. Initial phase angle range from 0 to } \\
\text { 360, 1degree step, duration continue any time ,1 ms step.,1 V step of swells } \\
\text { and dips, Switching time of swells and dips less 100 } \mu \text { s. }\end{array}$ \\
\hline Rated Capacity & 90kVA \\
\hline $\begin{array}{c}\text { Output voltage } \\
\text { harmonic frequency }\end{array}$ & $2-50$,single or Any combination of harmonic \\
\hline
\end{tabular}

Table 2. Current-mode power quality disturbances device parameter

\begin{tabular}{|c|c|}
\hline rated voltage & AC400V $\pm 15 \%$ \\
\hline rated frequency & $50 \mathrm{~Hz}$ \\
\hline Connecting method & three-phase four-wire system \\
\hline Rated Capacity & RMS $<100 \mathrm{~A}$ \\
\hline Output harmonic current & $\begin{array}{c}\text { Three phase or single phase and balance or Unbalance harmonic current, } \\
\text { single output harmonic current }<100 \mathrm{~A}\end{array}$ \\
\hline Output harmonic order & $2-50$, single or Any combination of harmonic \\
\hline $\begin{array}{c}\text { Instantaneous response } \\
\text { time }\end{array}$ & Three-phase independent control, generate single harmonic \\
\hline $\begin{array}{c}\text { three-phase output } \\
\text { Unbalance }\end{array}$ & Then \\
\hline
\end{tabular}

Table 3. Phase shifter technology parameter

\begin{tabular}{|c|c|}
\hline Rated voltage & AC380V $\pm 10 \%$ \\
\hline Rated frequency & $50 \mathrm{~Hz}$ \\
\hline Connecting method & three-phase three -wire system \\
\hline Phase shift range & $0-45^{\circ}$ \\
\hline Phase shift step & $1^{\circ}$ \\
\hline Rated current & $45 \mathrm{~A}$ \\
\hline
\end{tabular}

Table 4. Other device technology parameter

\begin{tabular}{|c|c|}
\hline SSTS & $\begin{array}{c}\text { Rated current 300A, rated voltage AC380V, three-phase four-wire } \\
\text { system ,switching with earth wire }\end{array}$ \\
\hline FESD & $\begin{array}{l}\text { rated voltage AC380V, rated power } 250 \mathrm{kVA} \text {, energy storage switching time } \\
\qquad 2 \mathrm{~ms} \text {, DC bus voltage }<400-700 \mathrm{~V} \text {. }\end{array}$ \\
\hline DVR & $\begin{array}{c}\text { Rated voltage AC380V,response time }<2 \mathrm{~ms} \text {, rated current } 50 \mathrm{~A} \text {, three-phase } \\
\text { four-wire system }\end{array}$ \\
\hline APF & $\begin{array}{c}\text { Rated voltage AC380V, Rated compensate capacity 60A, effective filter } \\
\text { response time }<10 \mathrm{~ms} \text {, switching frequency } 20 \mathrm{kHz} \text {. }\end{array}$ \\
\hline STATCOM & $\begin{array}{c}\text { Rated voltage AC380V, Rated compensate capacity } 200 \mathrm{kVar} \text {, total response } \\
\text { time }<10 \mathrm{~ms} \text {, switching frequency } 15 \mathrm{kHz} \text {. }\end{array}$ \\
\hline
\end{tabular}




\section{Application of comprehensive experimental platform for custom power equipment}

The test results of SSTS,DVR and FESD is shown by different switch combination for different topology structure custom power equipment testing.

\subsection{SSTS testing}

Voltage-mode power quality disturbance device is set, three phase voltage reduce to 60 percentage, last for $60 \mathrm{~ms}$, initial phase angle $90^{\circ}$, set phase shifting angle $15^{\circ}$. Load is $250 \mathrm{~W}$ metal-halide lamp. Testing wave is shown in figure-7. Deep-yellow wave symbols C-phase voltage at QF11, green wave symbols C-phase voltage at QF9, Red wave symbols C-phase voltage at QF13. from fugure-7. we know that switching time of SSTS is $12.3 \mathrm{~ms}$. Metal-halide lamp flicks quickly in testing, its light has not been changed and snubbed out.

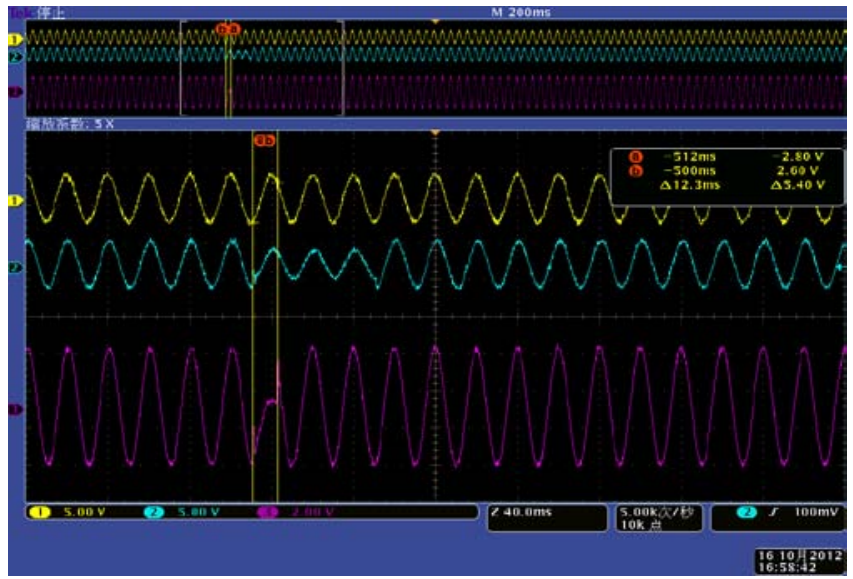

Figure 7. Experiment results of SSTS switching time

\subsection{DVR testing}

Voltage-mode power quality disturbance device is set, A-phase and B-phase voltage reduce to 30 percentage, last for $6 \mathrm{~s}$, initial phase angle 0 , Load is metal-halide lamp. $\mathrm{IA}=3.3 \mathrm{~A}, \mathrm{IB}=2.8 \mathrm{~A}$. Testing wave is shown in figure 7 and figure 9. Red wave symbols A-phase voltage at QF15, blue wave symbols A-phase voltage at QF16,from fugure-8 and figure-9 we know that compensating response time of SSTS is 1.69 ms. Its compensating time is $5.06 \mathrm{~s}$.

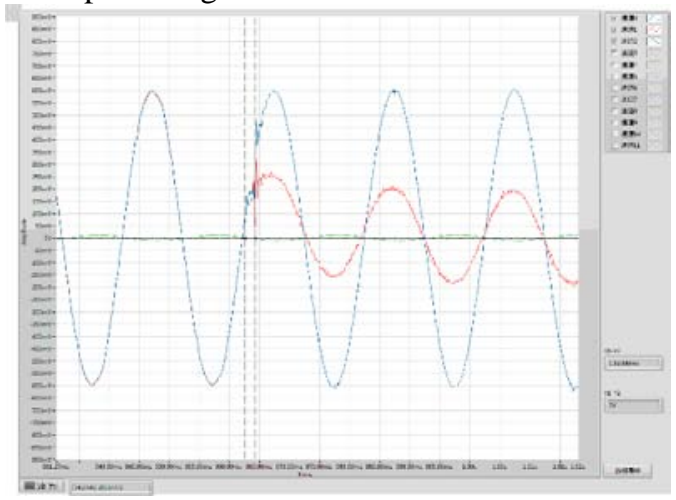

Figure 8. Experiment results of dynamic compensate response time 


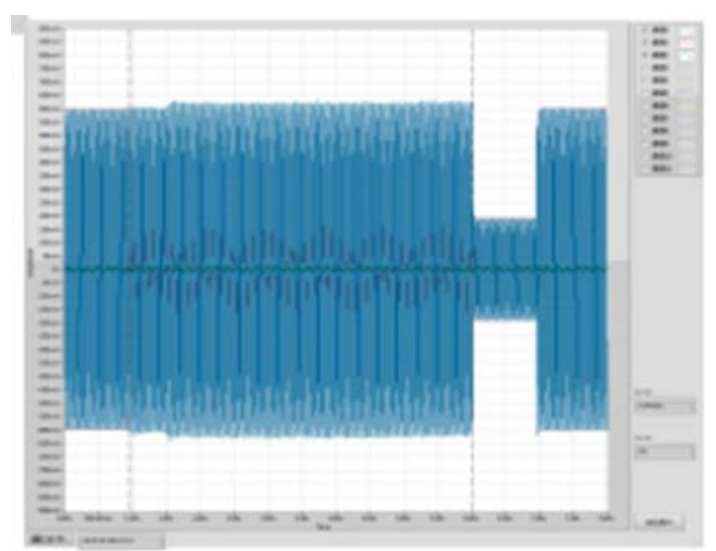

Figure 9. Experiment results of dynamic compensate time

\subsection{FESD testing}

QF10 is turned off to imitate FESD's power is disconnected. Load is metal-halide lamp. IA=10.9A, $\mathrm{IB}=12.9 \mathrm{~A}, \mathrm{IC}=12.1 \mathrm{~A}$. Testing wave is shown in figure-10 and figure-11. figure-10 at QF10, figure11at QF14. from figure -11,we know that output voltage has a recess in the case of its power is disconnecting .Then it return to normal value after $1.5 \mathrm{~ms}$.
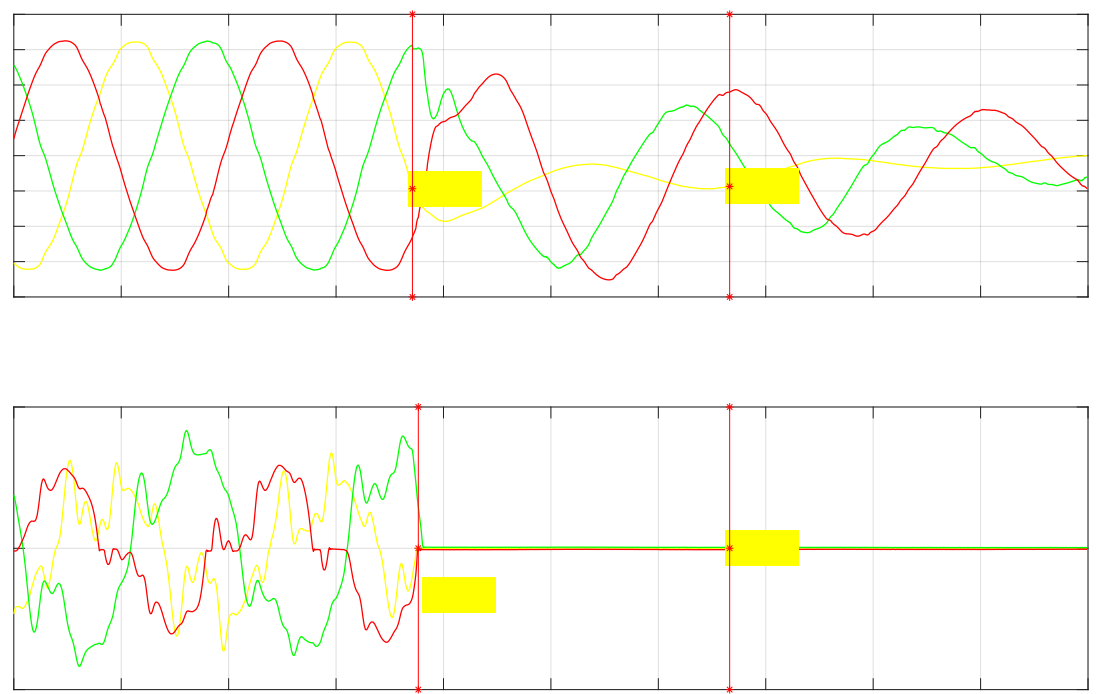

Figure 10. FESD voltage and current wave 

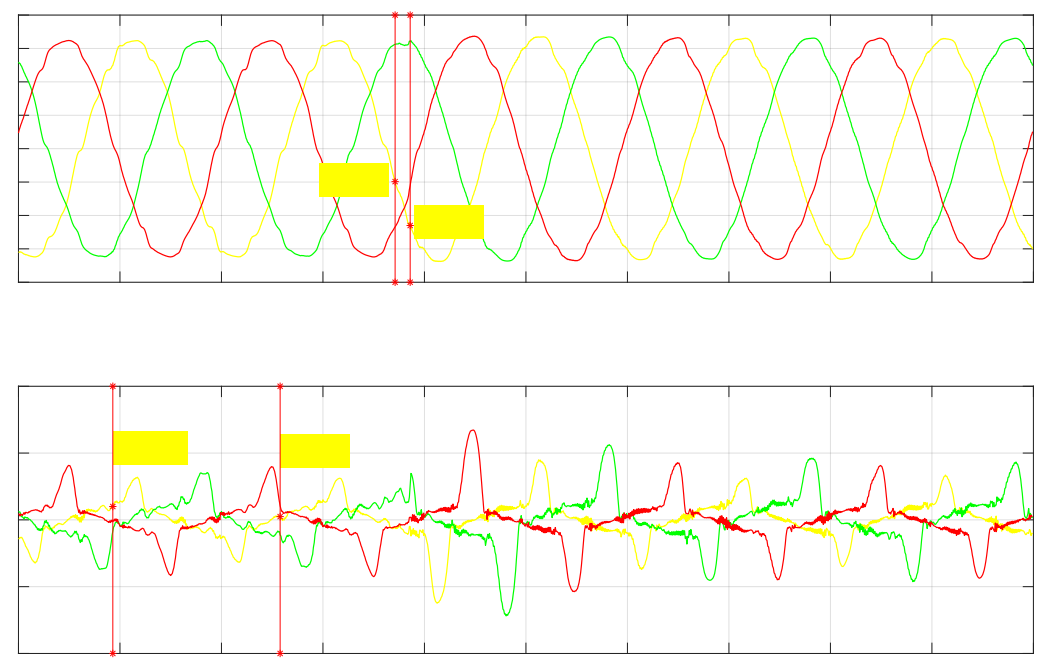

Figure 11. FESD output voltage and current wave

\section{Conclusion}

The designed Comprehensive Experimental Platform for Custom Power Equipment is mainly integrated five kinds of topologies structure custom power devices and three kinds of power quality disturbance devices.The experimental platform has the advantage of functional, flexible and expansion. It can provides not only test tools for exploring the performance of custom power equipment, but also entire performance verification platform for user custom power solutions, overall testing environment and industrial technical services for Equipment manufacturers and dealers. The testing platform Construction plays a positive role for the application of custom power technology in important users and sensitive users in Beijing .

\section{Reference}

1. Hingorani, N.C. Introducing custom power[J]. IEEE Spectrum, 32(6): 41-48.(1995)

2. Liu Zhiliang, Solid-state Transfer Switch in the Application of Chemical Industry Power Supply System[J]. Electric Power Science and Engineering, 27(4): 68-71.(2001)

3. Takeda M, Jochi S. Development of advanced solid-state transfer switch using novel hybrid switch devices[C]. Sixth International Conference on Advances in Power System Control, Operation and Management, November 2003, Hong Kong, China: 535-540.

4. Han Min-xiao, You Yong,Liu Hao, Principle and realization of dynamic voltage regulator(DVR) Based on line voltage compensate[J]. Proceedings of The Chinese Society for Electrical Engineering. 23(12): 49-53.(2003)

5. Vilathgamuwa D M, Wijekoon H M, Control and analysis of a new dynamic voltage restorer circuit topology for mitigating long duration voltage sags[C]. Industry Applications Conference, USA, 2,1105-1112.(2002)

6. Vilathgamuwa M, Ranjith P, Choi S. Performance Improvement of the Dynamic Voltage Restorer with Closed-loop Load Voltage and Current-mode Control. IEEE Trans on Power Electronics, 17(5): 824-834.(2002)

7. Nielsen J G, Newman M, Nielsen H, etal. Control and testing of a dynamic voltage restorer DVR at medium voltage level[J], IEEE Trans. on Power Electronics, 19(3): 806-813.(2004) 
8. Zhang Xiu-juan,LI Xiao-meng,JIANG Qi-rong, ZHOU Jin-ming. Main Circuit Design and Performance Test of Dynamic Voltage Regulator[J]. Power Electronic 2004, 38(2): 21-23.(2004) 